\title{
EL HUMANISMO
}

\author{
Carla Cordua
}

Premio Nacional de Humanidades 2011

Las humanidades son una creación del humanismo. Pero "humanismos" hubo varios, antes del que nos interesa aquí, algunos ya en la Edad Media y otros después de ella; entre los anteriores tuvo lugar un humanismo famoso en la corte de Carlomagno pero no produjo efectos duraderos fuera de esta corte. Para asociarlo a la situación presente no me referiré sino al humanismo del Renacimiento italiano, el que genera en los siglos XV y XVI los llamados studia humanitatis, origen de nuestras "humanidades". De manera que el humanismo y las humanidades en cuestión son de la misma época y están estrechamente relacionados entre sí. La palabra que genera los nombres de estos dos fenómenos históricos pertenece a la lengua italiana: "umanista", fue usado primero para designar a los profesores de retórica de algunas universidades italianas, y es vertida del vernáculo al latín. Y "humanismo", la expresión abstracta para el conjunto de ideas y preferencias del Renacimiento italiano, es una creación muy posterior de eruditos alemanes de principios del siglo XIX dedicados a estudiar los comienzos de la edad moderna.

¿Por qué estos movimientos que resultaron tan influyentes proceden de Italia? Italia había conservado una estrecha y persistente relación con la cultura clásica romana; el medioevo italiano estudia la ley romana, la gramática, la retórica y la oratoria latinas. Además, aunque no puede ser llamado un humanista, Tomás de Aquino establece en el siglo XIII la importancia de Aristóteles para la conceptualización sistemática del cristianismo. A partir del siglo XIV, los humanistas italianos ejercen una gran influencia sobre la educación elemental y universitaria de su país. Pronto las humanidades se convierten en un ciclo bien definido de materias de estudio: este ciclo incluye gramática, retórica, poesía, historia y filosofía moral. Son disciplinas 
dedicadas a asuntos mundanos o seculares, en contraste con las disciplinas del programa anterior, que enseñaba teología, metafísica, filosofía natural, medicina y matemáticas. Aunque no existe una incompatibilidad entre estos dos currículos, ellos son independientes uno del otro. Esta independencia no es anticristiana, como se ha dicho a veces, pero tampoco está interesada en la conservación de la cultura medieval. Característica del humanismo renacentista es la familiaridad con las lenguas y las literaturas griegas y latinas antiguas, a las que algo más tarde se agregarán las letras en hebreo. Los estudiosos derivaron sus ideales estilísticos y estéticos de modelos clásicos y acabaron difundiendo ampliamente cierto menosprecio hacia la Edad Media, convencidos de que su propia creatividad y grandeza dependía de la conexión que mantenían con las magníficas culturas antiguas. La poesía era considerada un arte que se dejaba enseñar y aprender, tal como las artes retóricas y epistolográficas. Las novedades producidas por la cultura vernácula renacentista eran sumadas al tesoro de lo heredado; así la "novella" en italiano, por ejemplo, un género narrativo nuevo, fue a menudo traducida del vernáculo al latín por los humanistas. Entendían que lo digno de conservación y de ser modelo de obras futuras debía ser honrado mediante su versión en una lengua antigua. Los modelos clásicos dieron lugar a una vasta literatura de aplicación inmediata: poesía de ocasión, discursos y cartas, elogios de los príncipes y de los poderosos, etc.

La época a la que nos referimos se siente nueva y capaz de las hazañas más difíciles y riesgosas. En su conciencia de sí, ella es un redescubrimiento del hombre, o un renacimiento, como más tarde se decidió llamarla. La más exaltada versión de las posibilidades del hombre, de la extensión de su libertad para pensar y hacer, la encontramos en la llamada Oración sobre la dignidad del hombre de Pico Della Mirandola, de fines del siglo XV. Comienza por una alabanza del hombre que en parte se basa sobre discursos antiguos acerca del mismo asunto. El hombre como inventor de las artes y las técnicas, como poseedor de la razón y del lenguaje, como semejante de Dios, etc. son temas que se vuelven a recoger en la Oración de Pico. Pero éste destaca sobre todo la libertad humana: el hombre carece, sostiene, de una naturaleza fija. Ello hace posible que su vida dependa solo del libre arbitrio del mismo. Tampoco tienen los hombres un puesto determinado en la jerarquía de los seres del mundo, sino constituyen, más bien, algo así como un mundo aparte. Cito: ¡Oh suprema generosidad de Dios Padre, oh la más alta y maravillosa felicidad del hombre! A él le ha sido concedido tener todo cuanto elige y ser todo cuanto quiera ser... ¿Quién no admiraría a nuestro camaleón?... Si cierta 
ambición sagrada invade nuestras almas, de modo que, no contentos con lo mediocre, aspiramos a lo más alto, debido a que podremos si lo deseamos, nos esforzaremos con todas nuestras fuerzas hasta obtenerlo.

La idea del individuo como un microcosmos que se hace a sí mismo entraña las nociones de la autosuficiencia y la universalidad de cada cual. La voluntad libre se puede dar estas condiciones por propia iniciativa. Si el hombre está dotado en principio para valerse de todas las posibilidades de ser y si elige cultivarlas realizará la plenitud de su vocación universal y la autonomía de quien se basta a sí mismo. Cito un pasaje en el que Pico dice lo siguiente, recomendando estudiar todas las filosofías: "Es parte de una mente angosta confinarse solo al Pórtico o a la Academia. Nadie puede elegir adecuadamente lo que le conviene de todas las filosofias si no se ha familiarizado antes con todas ellas. Además, considérese que en cada escuela hay algo distintivo de ella que no tiene en común con las demás".

Encontramos todavía esta ambición humanística del individuo como microcosmos entre los ideales de Goethe, tres siglos después de Pico Della Mirandola, y, aún más sorprendente, cincuenta años más tarde, hay otra versión de la misma en la obra de Carlos Marx, que anuncia que en la sociedad comunista que seguirá a la dictadura del proletariado, los trabajadores podrán, después de aportar su trabajo a la sociedad, cultivar todas sus más diversas potencialidades: se harán músicos, jardineros, poetas, médicos y exploradores en su tiempo libre. El humanismo representativo de esta idea del hombre pronto será objeto de crítica desde varios frentes diversos. Tratarán de refutarlo sobre todo y en primer lugar los pensadores cristianos que condenarán la soberbia y las excesivas pretensiones que lo caracterizan. La obra de Pascal, por ejemplo, constituye un poderoso recordatorio de lo que el pensador llama "la miseria del hombre", que no pasa de ser una criatura de un día que, ocultándose la muerte, consigue aturdirse provisoriamente y vivir aquí a su antojo, como si no supiera que la insignificancia del individuo será sometida a un juicio final severo después de la muerte.

Lo interesante de la amplia y duradera influencia de la inspiración humanística reside en que, aun allí donde algunos han abandonado las ideas de la libertad y la universalidad del hombre o no han consentido nunca en adoptarlas, las instituciones educativas tienden en general a conservar las humanidades como materias de enseñanza. Su variedad y carácter selecto sirven a la formación de personalidades autónomas, dueñas de sí y destinadas a altos designios. El divorcio de los dos lados del humanismo renacentista, el referente a la condición del hombre, por un lado, y sus efectos sobre los 
estudios necesarios para desarrollar las aptitudes humanas, por el otro, afecta poco al carácter y los contenidos de los programas educativos destinados a formar a los nuevos miembros de las clases emergentes de la sociedad moderna en gestación.

En efecto, como programa educativo de ciertos sectores sociales, los estudios humanísticos sobreviven a muchos cambios históricos. En los siglos XVII y XVIII formarán a los jóvenes, no ya para orientarse conforme a modelos admirables en un mundo nuevo pletórico de posibilidades no realizadas, sino como incorporación a la sociedad burguesa en proceso de definición. Una educación en los clásicos, que requiere conocer lenguas muertas y obras de poetas y sabios antiguos, debido a que separa del vulgo ignaro, resulta indispensable para los hijos de las clases pudientes. Cultos y refinados, los herederos de la burguesía y los aspirantes a llegar a serlo parecerán haberse ganado sus privilegios cuando se los compara con la tosquedad de las clases inferiores. De manera que la formación en las humanidades, además de los beneficios íntimos que otorga al individuo que recibe esta educación, se convertirá a la vez en señal inequívoca de cierta posición social y en la aparente justificación de que los portadores la ostenten actualmente. Algunos críticos actuales del programa educativo de raíz renacentista se refieren al humanismo despectivamente: era como el ideal que podría tener un club de lectores en el que uno es aceptado como socio si prueba que ha leído a los clásicos greco-romanos.

La formación humanística representará en todas partes a la libertad desinteresada, no utilitarista; en particular allí donde sus beneficiarios no están demasiado urgidos a abandonar temprano los estudios para ganarse la vida. Se supone que tales estudios, combinados con determinadas circunstancias sociales, le ofrecen al estudiante un plazo prolongado para crecer y aprender, y para prestar atención a sus voces interiores que le revelarán quién es y lo que le cabe esperar de la vida. Estas y otras posibles funciones sociales que las humanidades pueden prestar circunstancialmente no deben impedir que se les reconozca su valor intrínseco: conocer a los clásicos de primera mano será, aparte de toda otra consideración, un enorme golpe de suerte para aquellos a quienes la sociedad les concede la oportunidad de lograrlo. La idea de que el hombre se hace lo que llegará a ser gracias a la cultura heredada se independiza de su origen renacentista para convertirse en el ingrediente principal de la conciencia histórica que madurará en los siglos XVIII y XIX.

Pero, desde el siglo XVII en adelante, varios aspectos de la manera renacentista de pensar son objetos de crítica en nombre de posibilidades 
de la modernidad, que hará sentir su influencia contrapuesta a lo largo del siglo. La conquista de la naturaleza por la ciencia de nuevo cuño introduce el proyecto ingente de cambiar la suerte del hombre mediante la conducción sabia de las energías naturales puestas al servicio de fines humanos. Lo que Bacon y Descartes llamaron "el reino del hombre en la tierra" es un proyecto colectivo destinado a cambiarle la vida a la humanidad toda. No a reservar sus beneficios para un grupo selecto. La importancia suprema del individuo plenamente desarrollado comienza a ser desplazada por grandes vuelcos históricos. Esperando grandes beneficios de las ciencias del mundo físico y de las técnicas derivadas de ellas, lo que importa no es el refinamiento sino la confiabilidad del conocimiento, su seguridad. La razón humana, de la que depende la investigación de la naturaleza, será puesta a prueba ahora. Descartes investiga y diseña un tratamiento metódico para ella, capaz de garantizar los resultados que produce. Es preciso despojar a la mente de todos sus contenidos adquiridos aleatoriamente con el fin de prepararla para pensar sin la posibilidad de equivocarse. El pasado y su herencia pueden desaparecer sin consecuencias, el hombre moderno se basta a sí mismo si aprende a pensar metódicamente.

La empresa cartesiana de devolver la razón al punto cero para hacerla capaz de controlar todas sus operaciones, inaugura una larga época de vigencia del ideal de la tabla rasa en varias áreas de la cultura. Una de las primeras formas de la aspiración a establecer un presente que se deshace radicalmente del pasado es la idea de modernidad como un tiempo nuevo que carece de modelos dignos de imitarse. El humanismo se entendía como la recuperación de un período culminante de la historia humana, capaz de darle a las épocas posteriores la medida máxima de lo humanamente posible. Las ciencias modernas no reconocen precedentes metódicos: su novedad radical, su capacidad de descubrir verdades inéditas y de producir efectos inauditos, son su carta de presentación y el motivo de las grandes esperanzas que despierta. Desde sus comienzos las ciencias de la naturaleza se ven como una revolución tanto del saber como del poder humano sobre sus circunstancias terrenales. No reconocen autoridades ni ciencias previas. La racionalidad moderna queda ligada, por su radicalismo, al mito del retorno al punto cero en el que un hombre carente de herencia, de predecesores, es capaz, sin embargo, de actuar fecundamente, garantizado por el vacío inicial y por el método preestablecido para avanzar al futuro deseable.

Como si guardar tradiciones fuese incompatible con la permanente necesidad de innovar, la influencia modernista operó frecuentemente desde 
la convicción simplista de negar el valor del pasado. Sin ver que desnudar a los hombres de toda herencia equivale a privarlos de todo, de costumbres, de lenguaje, de instituciones. En un siglo en que la historicidad de la vida humana se ha vuelto un lugar común y en el que la capacidad del hombre para configurar un mundo propio está a la vista de todos, resulta extraño alimentar la ilusión de que se lo puede privar precisamente de aquello en que reside su condición básica. Ser humano es ser histórico-cultural de parte en parte. Sin embargo, los modernos suelen poner su confianza en una utopía: la de una transformación cabal e instantánea de todo a la vez. En Europa sobrevivieron las humanidades hasta cierto punto, a pesar de las influencias del modernismo utópico, los ideales de la individualidad independiente y de la educación que desarrolla el universo de las capacidades naturales de la persona. En este sentido, después de que el humanismo renacentista que genera el programa de las humanidades pierde su vigencia original, su programa educacional subsiste y cumple con la tarea de cultivar la multiplicidad de las dotes individuales. La especialización de las personas cuyo trabajo será requerido por el orden social moderno debe estar precedida por el cultivo y la maduración de la diversidad de las posibilidades humanas. Sin este blindaje humanístico de la personalidad en formación, el individuo caerá en la estrechez de una existencia amputada desde el comienzo de su desarrollo.

Entre nosotros, cortos de historia, recuperados solo a medias de la dependencia del imperialismo europeo que inventó nuestras nacionalidades según su conveniencia, las ideas y las instituciones recibidas del pasado colonial han sufrido ciertas deformaciones. El humanismo renacentista y su subproducto, las humanidades, las que forman parte todavía de nuestros sistemas educativos, se conservan mezcladas con elementos incongruentes que las tornan confusas y las debilitan. En todo caso, las humanidades que tenemos no repiten en este lado del mundo a sus modelos originales. Tal vez los elementos predominantes de la relativa continuidad de Europa en la América Hispánica sean la lengua castellana y el cristianismo. Pues las humanidades que se practican entre nosotros se han deshecho del cordón umbilical que las ligaba al clasicismo antiguo. El aprendizaje del latín y el griego nunca fueron considerados como requisitos para cursar la educación secundaria en las materias llamadas humanísticas ni para ejercer las profesiones humanísticas de la enseñanza, de la creación literaria y artística, de la formación espiritual de los americanos educados aquí. Sin latín y griego, la herencia greco-romana se tornó rápidamente en riqueza remota y exótica. Los pocos lingüistas y filólogos que conocen estas lenguas no son un elemento influyente en la cultura 
vernácula y solo raras veces ejercen como profesores que las difunden más allá de los límites de su propia profesión.

A pesar de todos los obstáculos sufridos por el trasplante de la cultura europea a las Américas, algunos girones que se han desprendido del ideario humanístico europeo aún se conservan entre nosotros y nos importan decisivamente. Por ejemplo, la noción general del valor formativo de la imitación de modelos. En vez de enseñar mediante reglas, digamos, a escribir en la propia lengua, a hablar con claridad y elocuencia, a pensar críticamente, etc., enseñar lo mismo mediante modelos concretos en los que se cumplen estas habilidades de manera sobresaliente. La educación que se vale de casos ejemplares, dando a conocer a personas notables y familiarizando con obras memorables, se vale de un método formativo mucho más atractivo que la que se limita a recomendar conductas en abstracto y a enseñar reglas y valores separados de toda circunstancia real. En vez de recomendar o de predicar la virtud de la veracidad, cosa que habitualmente resulta completamente inútil, se puede elegir el camino alternativo de dar a conocer casos singulares entroncados en situaciones reales en los que se ve que la práctica de aquella virtud ha engendrado a una persona excepcional que protagonizó una historia memorable. Mucho mejor que las recomendaciones de los mayores y los maestros, es el conocimiento y la contemplación de un modelo meritorio. El patrocinio y exhibición de modelos fue un método de educación anterior al Renacimiento, popularizado por órdenes católicas que proponían la imitación de Cristo como modo de vida. El método de enseñar mediante modelos fue adoptado luego por los humanistas que eligieron a los grandes pensadores, artistas, héroes y políticos de la Grecia y la Roma antiguas como fuentes de inspiración humana.

Pero el nacionalismo chileno e hispanoamericano en general, aunque a veces ha querido conservar la idea de enseñar las humanidades a las nuevas generaciones presentándoles ejemplos de obras y de personas famosas, ha concebido la ambición de que los modelos deben proceder de la patria chica de los que enseñan y aprenden. El nacionalismo, en cuanto adopta una postura defensiva frente a lo extranjero, milita inevitablemente en las filas de los partidarios de dividir a la humanidad en patrias diversas. El ideal renacentista de una humanidad por la que circulan libremente el pensar y las obras de los mejores hombres que han existido en la historia, aparte de sus nacionalidades, sus diferencias religiosas, políticas, lingüísticas, etc., es frontalmente contrario a las divisiones e intereses nacionalistas. No proponemos una beatería grecoromana para consumo local; estamos bastante lejos de los studia humanitatis 
de la Italia renacentista. Pero la idea central de estos estudios todavía puede servir para protegernos del trato que reciben el hombre y la humanidad toda de parte de muchas disciplinas que se quieren científicas en la actualidad.

En efecto, lo contrario del hombre humano al que están destinadas las humanidades, es el hombre de que tratan la antropología contemporánea y otras disciplinas con arrestos doctrinarios muy poco científicos. El estudio del hombre como ser natural, esto es, como parte de una naturaleza que comparte como animal con otras especies que la suya, es un estudio perfectamente legítimo mientras se mantiene dentro de los límites de su punto de vista bastante parcial. Cuando se extralimita y pretende cubrir aquellos sectores de la vida y la actividad humanas que no caen dentro del campo de su competencia, la ciencia ha dejado de ser lo que pretende, para dar lugar a la charlatanería y la propaganda ideológica. Ni la antropología, ni la biología, ni la psicología naturalista, ni muchas otras disciplinas que comparten el punto de vista antropológico que se ocupa del hombre como objeto o cosa, pueden referirse buenamente a las dimensiones histórico-culturales que están en juego allí donde lo que importa es el pensamiento, la educación, la moralidad, la convivencia política, el lenguaje, las artes, en suma, el patrimonio espiritual de una humanidad que tiene futuro debido a que no ha perdido el contacto con la tradición específica que lo separa de la naturaleza y los animales. Mientras los estudios humanísticos sean capaces de mantener viva la noción del lugar preciso y bastante honroso que le corresponde a la humanidad en el mundo, conservarán un nexo potente con su origen en la Europa renacentista. Este nexo servirá para sanar las heridas que la conquista y colonización europea de las Américas han dejado entre nosotros. Podremos decir, parafraseando a Neruda: se llevaron el oro pero nos dejaron una idea de humanidad que nos defiende de las confusiones que derivan de unas ciencias que, olvidando su compromiso con la verdad, no saben respetar sus propios límites.

¿Qué dirán de sí mismos y de su asunto los estudios humanísticos que los diferencie claramente de otras disciplinas que se refieren a la humanidad? Dirán que son estudios que se refieren a un ser que se caracteriza por los riesgos que toma sobre sí, por ser alguien que se expone a poner a prueba los límites de su especie y que, ocasionalmente, prefiere exceder tales límites. Además de tener rasgos comunes con otras especies naturales, se separa de todas porque su conducta excede estas coincidencias parciales con lo animal. ¿En qué consiste tal exceso humano capaz de transformar la propia animalidad? El hombre se expone continuamente más allá de lo que ha sido. Este exceso es peligroso, resulta de una actividad no ejercitada antes y no tiene 
garantías de salir bien. Exponerse en el sentido literal de ponerse fuera de lo heredado y conocido, en el sentido de exceder límites, es lo propio humano. Tanteando lo posible, lo que puede llegar a ser el futuro es lo que nos obliga con el pasado. No en el sentido de que es aquello que queremos repetir, sino en otro distinto. El pasado exhibe otros tanteos, otras extralimitaciones, que nos ayudan a leer nuestras propias posibilidades de ser que todavía no están disponibles para valerse de ellas. En el espíritu de este tipo de educación humanística es que nos resulta hueca la famosa frase: "Nada humano me es ajeno". Resulta obvio que quien la enuncia no sabe lo que lo espera. 